\title{
PERAN SIDIK JARI DALAM MENGUNGKAP KASUS TINDAK PIDANA PEMBUNUHAN
}

\author{
Sujarwo \\ Polres Blitar \\ Email: mizanjurnalilmuhukum@gmail.com
}

\begin{abstract}
ABTRAK
Kepolisian Negara republik Indonesia, saat ini sudah melakukan upaya pembenahandan pembaharuan baik kedalam maupun keluar, sehingga harapaan masyarakat terhadap kepolisian bisa dilaksanakan dengan sebaik-baiknya.Kepolsiian sebagai pelindung dan pengayom masyarakat, harus bisa mewujudkan setiap apa yang di harapkan masyarakat, sehingga masyarakat merasa terlindungi,tentram dan aman.

Sekarang ini banyaknya kejadian perkara tindak pidana pembunuhan yang dilakukan dengan sadis, contoh korban dimutilasi/dipotong-potong harapan pelaku, bahwa perbuatnya itu tidak akan terungkap.Namun dari pihak Kepolisian khususnya unit identifikasi harus berjuang dan bekerja keras untuk melakukan upaya mencari identitas korban yang tidak ditemukan atau pelaku yang hanya meninggalkan jejak jari di tempat terjadinya perkara.Maka unit identifikasi Kepolisian menggunakan alat Mambis,sehingga identitas korban atau yang diduga tersangka bisa ditemukan melalui alat mambis, selama kulit jari korban tidak rusak, maka identitas bisa dibaca melalui alat mambis dan akan ditemukan identitas korban sesuai E KTP yang dipunyai.Alat Mambis ini merupakan alat yang bekerjasama dengan Departemen dalam Negeri, sehingga setiap orang yang sudah melakukan E KTP, maka bila mennggunakan alat ini, maka identitas akan muncul sesuai E KTP.

Dengan demikian harapan masyarakat terhadap perkara pembunuhan yang dilaporkan, akan dilakukan ungkap secepatnya.

\section{ABTRACT}

The Polisce of The Republik of Indonesia is nom making efforts to improve and renew both inside and out,so that the public wishes for the police can be implemented well.Police Department as protector of society must be able to realize everything expected by the community, so the people feel protected,peaceful and secure.

Nowadays, the number of criminal cases of murder are committed with sadism, for the example the victim ,mutilated/dismembered.The perpetrator hopes that this actions will not be revealed. However, the police especially the identification unit must struggle and work hard to make efforts to find the identity of the victims who do not found, or a perpetrator who only leaves a fingerprint at the scene of the case. So the police identification unit uses mambis tool,so that the identity of victim or considereded suspect can be found through the mambis tool, as long as the victim,s finger palms are not damaged,so the identity can be read through the mambis tool and the identity of the victim can be found according to their E-ID CARD. Mambis tool is a tool which is in cooperation between police department and the ministry of home affair,so that everyone who has made an E-ID card,if use this tool,the identity will appear according to E-ID CARD.

possible.

Therefore, the public,s expectation of thereported murder/homicide case will be revealed as soon as
\end{abstract}

\section{A. PENDAHULUAN}

Melakukan upaya hukum sampai maksimal. Kepolisian dalam melaksanakan tugas untuk melakukan upaya penagakkan hukum harus secara maksimal dan didukung kemampuan perindividu yang sangat penting sehingga tugas-tugas untuk ungkap suatu perkara harus bisa berjalan lancer dan berhasil, sesuai harapan para korban khususnya masyarakat yang menjadi korban tindak pidana yang terjadi.

Kepolisian Negara Republik Indonesia atau anggota Kepolisian Indonesia, setelah adanya laporan Polisi atau laporan 
adanya suatu tindak pidana yang terjadi , selanjutnya petugas melakukan proses penyelidikan dan penyidikan yang merupakan serangkaian kegiatan awal seorang penyidik yang tidak bisa dipisankan, miskinpun tahapan-tahapan yang berbeda. Apabila proses penyelidikan disatukan dengan penyidikan, maka akan terlihat adanya suatu kesinambungan tindakan yang dilakukan Kepolisian, sehingga akan memudahkan proses selanjutnya.

Kepolisian sesuai harapan masyarakat dan sesuai undang-undangan mempunyai wewenang :

a. Memelihara keamanan serta ketertiban umum, mengandung pengertian Represif atau tugas terbatas yang kewenangannya dibatasi oleh Kitab Undang-Undang Hukum acara pidana ( KUHAP).

b. Bertugas mengayomi adalah tugas yang luas, tanpa batas, boleh melakukan apa saja asal keamanan terpelihara dan tidak melanggar hukum itu sendiri ( mengandung pengertian preventif).

Penegakkan hukum didalam system peradilan pidana bertujuan untuk menanggulangi setiap kejahatan . hal dimaksud agar setiap tindakan-tindakan yang melanggar aturan hukum dan peraturan perundang-undangan serta membuat kehidupan masyarakat menjadi aman,tentram dan terkendali dan masih dalam batas-batas toleransi masyarakat. Hal tersebut sesuai dengan pedapat dari Mardjono Reksodipoetro, bahwa system peradilan pidana adalah system dalam suatu masyarkat untuk menaggulangi masalah kejahatan.Menanggulangi diartikan sebagai mengendalikan kejahatan agar berada dalam batas-batas telorasi masyarakat.Berdasarkan pada pokok-pokok pikiran tersebut diatas maka kajian ini mencoba mamahami usaha menanggulangi kejahatan menjadi sasaran utama dari hukum pidana, serta bagaimana system peradilan pidana sendiri bekerja, baik dari segi hukumnya maupun dari segi pelaksanannya.

Dengan berlakuknya Undangundang Kepolisian No 2 tahun 2002, tentang Kepolisian Negara Repubublik Indonesia, Maka undang-undang Kepolisian No 28 tahun 1997, tentang Kepolisian Negara Republik Indonesia tidak berlaku lagi.Oleh karena itu Undang-uandang ini diharapkan dapat memberikan penegasan watak Kepolisian Negara Republik Indonesia sebagaimana dinyatakan dalam Tri Brata dan Catur Prasetya sebagai sumber nilai Kode Etik Kepolisian yang mengalir dari falsafah Pancasila.

Dalam ilmu tentang sidik jari ( daktiloskopi ) menyebutkan bahwa tidak ada manusia yang mempunyai sidik jari yang sama dan tidak akan berubah seumur hidupnya.Karena sifatnya yang permanen maka sidik jari seseorang dipergunakan sebagai sarana yang mantap dan menyakinkan untuk menentukan jati diri seseorang. Sidik jari merupakan sarana terpenting untuk mengidentifikasi seseorang,pengambilan dan pengumpulan sidk jari tidak dapat dilakukan oleh sembarang orang, melainkan benar-benar dilakukan oleh tenaga ahli yang dalam hal ini adalah pihak kepolisian ( yang mempunyai keahlian khusus didik jari ).Sidik jari merupakan merupakan identitas pribadi yang tak mungkin ada yang menyamainya.Karena keunikkannya tersebut sidik jari dipakai oleh Kepolisian dalam penyidikan kasus kejahatan ( forensic), oleh karena itu pada saat terjadinya suatu kejahatan ,TKP akan diamankan dan dilarang bagi siapa saja masuk karena dikawatirkan akan merusak sidik jari pejahat yang mungkin tertinggal dibarang bukti yang ada di TKP.Kemampuan sidik jari sebagai identitas seseorang tidak diragukan lagi, bahkan metode ini dilakukan diseluruh dunia.Pada mulanya sidik jari masih terbatas pada pelaku tindak pidana saja, guna disimpan sebagai arsip di Kepolisian, hal ini untuk memudahkan Kepolisian dalam proses penyidikan apabila ditemukan sidik jari latent yang tertinggal ditempat kejadian perkara dan kemudian dibandingkan dengan arsip yang telah dimiliki oleh pihak Kepolisian Apakah sidik jari Latent yang ditemukan ditempat kejadian perkara identik atau tidak dengan sidik jari pembanding yang dimiliki oleh pihak Kepolisian, apabila identik maka Kepolisian telah memiliki identitas pemilik sidik jari latent yang tertinggal ditempat kejadian perkara,akan tetapi bila apabila tidak identik dengan sidik jari pembanding yang dimiliki Kepolisian, maka tugas Kepolisian adalah mencari pemilik sidik jari latent yang 
tertinggal di tempat Kejadian perkara( TKP ) tersebut atau tempat tindak pidana tersejadi.

\section{Permasalahan.}

\section{a. Apakah Kepolisian dalam menggungkap tindak pidana pembunuhan selalu menggunakan identifikasi sidik jari.}

Kepolisian dalam melakukan upaya penegakkan hukum pada era sekarang ini diperlukan ke pengetahuan,pengalaman dan keteletihan untuk bisa melakukan penggungkapan setiap perkara pidana yang terjadi.Petugas Kepolisian khususnya anggota Reserse harus benar-benar mempunyai kemampuan yang lebih, dan lebih khusus lagi anggota identifikasi kepolisian harus ,menguasai dan mampu mengaplikasikan di setiap adanya kejadian perkara (TKP) yang ada.Dengan dukuang alat yang memadai diharapkan atau harapan masayarakat/korban tindak pidana, petugas identifikasi bisa melaksanakan tugasnya, sehingga bisa melakukan upaya tindakan mulai dari olah TKP sampai bisa melakukan penangkapan terhadap pelaku tindak pidana yang terjadi atau yang dilaporkan oleh masyarakat.

Peran petugas identifikasi Kepolisian sangatlah diperlukan untuk melakukan upaya penggungkapan beberapa perkara pidana yang terjadi.Dalam perjalan melakukan upaya penyelidikan bila petugas menemukan perkara yang kurang bukti, kurang saksi, maka peran petugas identifikasi untuk mencari jejak telapak tangan atau kaki yang ditinggalkan pelaku pidana sangat dibutuhkan dan diperlukan.Dengan demikian ketelitian dan ketelatenan petugas identifikasi untuk mencari jejak telapak tangan atau kaki sangat diperlukan dengan ditemukan jejak tersebut, maka upaya penyelidikan dan penyidikan petugas Kepolisian untuk menggungkap perkara pidana semakin muda dan jelas. Diera sekarang ini Kepolisian Negara Republik Indonesia khususnya petugas identifikasi berupaya terus mengembangkan pengetahuan tentang identifikasi sidik jari,karena identifikasi bisa digunakan sebagai alat bukti dalam sidang perkaran pidana.Seorang petugas identifikasi yang datang ke Tempat terjadinya Perkara ( TKP), harus mempunyai pengetahuan awal untuk mengamati TKP dan sekiranya, sehingga TKP tidak rusak dan keaslinya TKP harus dijaga, sebab awal penyelidikan dan penyidikan berawal dari TKP.

Suatu perkara pidana tidak selalu menggunakan identifikasi sebagai sarana untuk melakukan upaya menggungkap perkara pidana dengan alasan :

- Pelapor tahu persis kejadiannya/tahu pelakunya.

- Adanya saksi lain selain korban yang mengetahui perkara pidana tersebut.

- Adanya barang bukti di TKP yang ditinggalkan pelaku.

- Adanya pelaku yang jelas identitasnya.

b. Hambatan apakah, yang dialami kepolisian dalam menggunakan sidik jari identifikasi dalam menggungkap perkara tindak pidana pembunuhan.

Pada ero globalisasi sekarang ini dan kemajuan teknologi saat ini Kepolisian mempunyai tugas yang sangat berat dalam penagakan hukum.Petugas identifikasi Kepolisian dalam melakukan upaya identifikasi mempunyai beberapa kendala dilapangan :

1. Kendala diluar Kepolisian ( kendala eksternal)

a) Kekurangan tahuan masyarakat akan petingnya penanganan Tempat Terjadinya perkara (TKP).

Pada umumnya masyarakat begitu melihat dan menegetahui terjadinya tindak pidana,dengan keingin tahunnya medatangi TKP secara sepontan dan akan memegang barang-barang, dengan tidak sengaja merusak jejak telapak kaki /tangan yang ditinggalkan pelaku di TKP.Dengan adanya perbuatan masyarakat itu akhirnya petugas identifikasi merasa kesulitan, sebab barang bukti dan TKP sudah dalam keadaan rusak.

b) Faktor waktu.

Masyarakat atau korban bila lapor ke Kepolisian terlampat,maka keadaan TKP ( tempat terjadinya perkara ) dimungkinkan akan rusak, sehingga keutuhan TKP kurang terjamin.

c) Faktor cuaca.

Faktor cuaca ini menjadi kendala bagi petugas identifikasi, bila TKP berada diluar rumah, maka jejak 
telapak tangan/kaki akan hilang terkena hujan dan barang bukti di TKP juga bisa berpindah dari tempat awal.

2. Kendala dalam Kepolisian ( kendalan internal ).

a) Kurang teliti atau lengahnya terhadap suatu obyek.

Anggota identifikasi kalau medatangi TKP kurang teleti dan kurang hatihati,terhadap barang bukti yang ada, sehingga hasilnya kurang maksimal.

b) Minimnya sarana dan prasarana petugas.

Petugas identifikasi saat sarana dan prasarana contohnya mobil identifikasi untuk medatangi TKP belum ada dan masih kurangnya beberapa kelengkapan identifikasi.

c) Meningkatkan kualitas petugas Identifikasi.

Pada saat ini petugas identifikasi perlu ditingkat dengan pelatihan masalah identifikasi, sehingga dalam menangani setiap perkara bisa maksimal artinya sesuai kemampuan.

d) Meningkatkan sarana dan prasanara.

Dalam melaksanakan tugasnya agar petugas identifikasi bisa berkerja sempurna dalam menangani TKP, maka keperluan sarana dan prasarana perlu dicukupi dan dilengkapi, sehingga dalam melakukan oleh TKP bisa berjalan dengan baik dan medapatkan hasil yang maksimal.

c. Apakah saat ini Kepolisian sudah memiliki alat idik jari yang kegunaannya sudah maksimal.

Di Kepolisian saat ini sudah ada fungsi indentifikasi, petugas identifikasi berperan untuk menemukan identitas korban atau tersnagka yang belum dikenali artinya pada saat kejadian di TKP tidak ditemukan identitas korban atau identitas tersangka.Maka saat itu peran petuga identifikasi diharapkan bisa menemukan korban atau tersangka yang tanpa identitas tersebut.Dalam ilmu identifikasi sidik jari ( daktiloskopi ) tidak ada manusia yang mempunyai sidik jari yang sama dan sidik jari manusia tidak akan berubah seumur hidupnya, karena sifat sidik jari manusia sangat permanen.Maka dalam mejalankan tugasnya petuga sidentifikasi harus benar- benar mempunyai pengetahuan dan kemampuan dalam mejalankan olah TKP.Khususnya perkara kejahatan pembunuhan olah TKP awal sangat diperlukan, dengan olah TKP yang baik maka akan bisa dilakukan untuk melakukan ungkap perkara pembunuhan tersebut.

Dalam pasal 14 ayat (1) Undangundang No 2 tahun 2002, tentang Kepolisian, bahwa salah satu tugas Kepolisian adalah menyelenggarakan identifikasi, kedokteran kepolisian, Laboratorium forensik.Dengan demikian tugas Kepolisian semakin berat sebab kejahatan sekarang ini juga semakin beraneka raga untuk menghilangkan jejak, sehingga petugas Kepolisian harus jeli dan teliti setiap melakukan oleh Tempat Kejadian Perkara.

Dalam ilmu identifikasi,ada tiga bentuk identifikasi :

- Bentuk busur (arch).

- Sangkutan (Loop).

- Lingkaran (Whort). Kemajuan Teknologi dalam menunjang tugas Kepolisian dalam mengumpulkan sidik jari sangat besar manfaatnya, seperti sistem INAFIS (Indonesia automatic fingerprint identification system ).Suatu sistem yang mengumpulkan data setiap individu atau warga negara Indonesia tidak terkecuali bayi yang baru lahir bisa direkam di data bese inafis.Penyimpanan data ini melalui Nomer induk Kependudukan ( NIK ).Dengan demikian setiap warga negera indonesia data bese di Kepolisian.Bekerja samanya Kepolisian dengan Departeman dalam Negeri ini sanagatlah membantu petugas Kepolisian untuk melakukan upaya identifikasi , jadi setiap orang yang melakukan kejahatan akan terekap di inafis Kepolisian.

\section{Tujuan Penelitian.}

a. Untuk mengetahui manfaat identifikasi sidik jari yang dilakukan Kepolisian Negara Republik Indonesia,dalam menggungkap perkara pidana.

b. Untuk mengetahui hambatan yang dialami kepolisian dalam menggunakan sidik jari identifikasi dalam menggungkap perkara pidana.

c. Untuk mengetahu apakah kepolisian sudah mememiliki alat identifikasi yang dan bisa digunakan sudah membantu proses penyidikan perkara pidana pembunuhan. 


\section{B. METODE PENELITIAN}

Metode yang digunakan penulis adalah penelitian yuridis normative yaitu dengan mengkaji dan menganalisa data sekunder yang berupa bahan hukum sekunder dengan memahami hukum sebaagai perangkat peraturan dan norma-norma positif dalam sistem hukum dikehidupan masyarakat, untuk mencapai keamanan,ketentraman dan keadilan dimasyarakat, serta menghilangkan rasa takut di masyarakat.

\section{HASIL PEMBAHASAN.}

Berdasarkan hasil penelitian, Kepolisian bertujuan untuk menegakkan hukum, melindungi,mengayomi masyarakat, sehingga tercipta suasana yang damai tercipta keadilan .Hukum harus ditegakkan artinya siapa yang melanngar harus medapatkan sangsi hukum dan kedepanan diharapakan masyarakat tidak melanggar hukum dan menyadari akan petingnya hukum dikehidupan masyarakat.

\section{KESIMPULAN}

Berdasarkan hasil penelitian yang telah dilakukan,mengenai peran sidik jari dalam rangka menggungkap khasus tindak pidana pembunuhan di Polres Blitar Kota,dapat dijelaskan sebagai berikut :

1. Peran Kepolisian dalam mengungkap tindak pidana pembunuhan menggunakan identifikasi sidik jari.

Kepolisian dalam melakukan upaya menggungkap perkara pidana pembunuhan tidak selalu menggunakan identifikasi sidik jari.Peristiwa pembunuhan bila sudah ada saksi,ada barang bukti dan yang diduga pelakunya jelas, maka tanpa menggunakan identifikasi sidik jari sudah bisa dilakukan penangkapan.Namun bila peristiwa pembunuhan, saksi tidak ada, barang bukti minim dan yang diduga tersangka belum diketahui dan di TKP ditemukan sidik jari, maka dengan dengan fungsi identifikasi bisa digunakan untuk menggungkap perkara pidana melalui alat identifikasi.
2. Hambatan yang dialami kepolisian dalam menggunakan identifikasi sidik jari.

Dengan banyaknya perkara pidana tindak pidana yang para pelaku dengan sadisnya membunuh dan memotong/mutilasi tubuh korban Unit identifikasi dalam melakukan pengungkapan pelaku tindak pidana pembunuhan berencana, menghadapi kendala-kendala :

a. Kendala dari luar Kepolisian

1. Kekurang tahuannya masyarakat sekitar tempat terjadinya perkara ( TKP).

2. Faktor waktu

3. Faktor cuaca.

b. Kendala dari dalam Kepolisian.

1. Kurang teliti atau lengah terhadap suatu obyek..

2. Minimnya sarana dan prasarana Kepolisian.

3. Kepolisian saat ini sudah memiliki alat identifikasi sidik jari yang kegunaannya sudah maksimal.

Kepolisian pada masa lalu dalam melakukan oleh tempat terjadinya perkara (TKP) hanya menggunakan alat yang manual dan sangat sederhana sekali .Dalam melakukan oleh TKP salah satu contoh hanya menggunakan serbu untuk bisa mengambil sidik jari yang tertinggal di benda/kaca, namun bila sidik jari pelaku atau tersangka ada di papan kayu petugas identifikasi sangat menemui kesuliatn untuk proses pengambilan sidik jari tersebut.Kepolisian sudah bisa mengadakan alat yang lebih baik dari sebelumnya bernama alat $\boldsymbol{M A M B I S}$.

\section{E. DAFTAR PUSTAKA}

Undang-undang Dasar Tahun 1945.

Undang-undang No 8 tahun 1981 ,tentang Hukum Acara Pidana. (KUHAP).

Undang-undang No 2 tahun 2002,tentang Kepolisian Negara Republik Indonesia.

Dasar Perkap No 12 tahun 2002,pasal 12,tentang oleh TKP.

Dasar perkap No 6 tahun 2010, pasal 20.

Undang-undang No 48 tahun 2009,tentang kekuasaan kehakiman. 
Arif,Barda Nawawi, bunga Rampi Kebijakan hukum Pidana,cetakan ketiga edisi revisi,citra aditya, Bandung 2001.

Beberapa aspek kebijakan penegakan dan penanggulangan hukum pidana,Bandung citra aditya 1998.

Prodjodikoro wirdjono,Azas-azas hukum pidana diindonesia,Pt Refika Aditama.Bandung 2003.

Hukum Pidana Nasional ,Pt Citra Aditya Bakti,Bandung 2005. 